Brazilian Journal

of Chemical

ISSN 0104-6632

Printed in Brazil

Engineering

www.scielo.br/bjce

Vol. 35, No. 03, pp. 835-846, July - September, 2018

dx.doi.org/10.1590/0104-6632.20180353s20170155

(cc) BY

\title{
PRODUCTION OF POLYUNSATURATED FATTY ACIDS BY MICROORGANISMS ISOLATED IN THE BRAZILIAN PAMPA BIOME
}

\author{
Denise Tonato ${ }^{1}$, Camila Marcuz ${ }^{1}$, Raquel G. Vendruscolo², Caroline Bevilacqua ${ }^{3}$, \\ Rodrigo J. S. Jacques ${ }^{3}$, Roger Wagner ${ }^{2}$, Raquel C. Kuhn ${ }^{1 *}$ and \\ Marcio A. Mazutti ${ }^{1}$ \\ ${ }^{1}$ Department of Chemical Engineering, Federal University of Santa Maria, Av. Roraima, 1000, \\ Santa Maria,97105-900, Brazil.denise.tonato@hotmail.com,camila_marcuz@hotmail.com, \\ raquelckuhn@yahoo.com.br, marciomazutti@gmail.com \\ ${ }^{2}$ Department of Food Technology, Federal University of Santa Maria, Av. Roraima, Santa Maria, \\ 97105-900, Brazil. raquelgvendruscolo@gmail.com, rogerwag@gmail.com \\ ${ }^{3}$ Department of Soil Science, Federal University of Santa Maria, Av. Roraima, 1000, Santa \\ Maria, 97105-900, Brazil. carolinebevi@gmail.com, rodrigo@ufsm.br
}

(Submitted: March 20, 2017; Revised: June 11, 2017; Accepted: July 5, 2017)

\begin{abstract}
One hundred fifty fungal strains were isolated from the Pampa biome for production of polyunsaturated fatty acids (PUFA). Microbial oil was produced by submerged cultivation at $120 \mathrm{rpm}, 28^{\circ} \mathrm{C}$ for 7 days. Seven strains showed the best results for lipids accumulation, and they were selected in order to evaluate the influence of the temperature $\left(15\right.$ and $\left.28{ }^{\circ} \mathrm{C}\right)$ on the lipid production and profile. The fungus Nigrospora sp. produced the highest lipid level: at $28{ }^{\circ} \mathrm{C}$ were produced $11.28 \%$ of lipids and $51.94 \%$ of PUFA and at $15{ }^{\circ} \mathrm{C}$ were produced $6.02 \%$ of lipids and $42.39 \%$ of PUFA. Plackett Burman design was performed to investigate the main effects of the temperature $\left(15-25^{\circ} \mathrm{C}\right), \mathrm{pH}(4.0-6.0)$, agitation (120-200 rpm), corn steep liquor $(5-15 \%(\mathrm{v} / \mathrm{v}))$ and sucrose concentrations $\left(60-180 \mathrm{~g} \mathrm{~L}^{-1}\right)$. The highest PUFA production $(55.75 \%)$ was observed at the lowest temperatures $\left(15{ }^{\circ} \mathrm{C}\right)$, whereas the maximum lipid production was $5.54 \%$ at $25^{\circ} \mathrm{C}$.
\end{abstract}

Keywords: Polyunsaturated fatty acids; Fungal strains; Submerged fermentation; Nigrospora sp.

\section{INTRODUCTION}

Recently in Brazil, the sustainable exploration of the biodiversity has been encouraged aiming at the discovery of microorganisms to be used as a source for commercially exploitable products as a strategy to create a fast and efficient way for scientific and technological development (Pyrlo et al., 2014). It is estimated that approximately $20 \%$ of the entire global biological diversity is present in the six Brazilian biomes. One of them is the Pampa biome, which is located in the Southern region of the country and is the most unknown of the Brazilian biomes in relation to its biodiversity (Lupatini et al., 2013). The knowledge of fungal diversity is especially important in Brazil as a way to protect such biomes through the

*Corresponding author: E-mail address: raquelckuhn@yahoo.com.br 
isolation and characterization of the missing fungal diversity (Sette et al., 2013). Among the products that might be obtained from the Brazilian biodiversity, the polyunsaturated fatty acids are important for human health, being identified as potential food additives or pharmaceuticals due to their biological activities (Béligon et al., 2016; Bellou et al., 2016).

Polyunsaturated fatty acids (PUFAs) are longchain fatty acids containing more than one double bond in their structure (Deelai et al., 2015; Pote and Bhadekar, 2014). Based on the position of the double bonds, they are classified as omega-3 ((3), omega- 6 ((6) and omega-9 ((9) fatty acids. Essential fatty acids (EFAs) are those that are required for optimal human health, but which are not synthesized by the body; they must be obtained from dietary sources (Béligon et al., 2016). These EFAs have been extensively used as dietary supplements for health and infant formulas (Deelai et al., 2015).

Currently, the major source of PUFAs is fish. However, their global stocks are gradually limited, resulting in inadequate production, in addition to the bad taste and odor of fish oil. Oleaginous microorganisms have the potential of being alternative sources of PUFAs for human consumption (Deelai et al., 2015). The oleaginous species such fungi, bacteria and yeast could accumulate lipid to more than $20 \%$ of their biomass (Ratledge and Wynn, 2002). Particularly, fungi are potential sources of PUFAs (Deelai et al., 2015); these microorganisms can accumulate a large amount of high-valued polyunsaturated fatty acids, such as the (-linolenic acid (GLA) and arachidonic acid (ARA) (Deelai et al., 2105; Mamatha et al., 2008).

Based on these aspects, the aim of this work was the screening of fungi from the Pampa biome regarding the production of polyunsaturated fatty acids. First, one hundred and fifty fungi were isolated and fermented for oil production. After choosing the most promising strain for production of PUFA, the influence of process variables on the amount of oil produced were investigated.

\section{MATERIALS AND METHODS}

\section{Fungi isolation and selection}

Fungi were collected from the above-ground parts of native herbaceous plants in different areas of the Pampa biome. The samples were stored in plastic bags and maintained at $4{ }^{\circ} \mathrm{C}$. Afterwards, the samples were transported to the Laboratory of Bioprocess, where the isolation of the fungi was carried out. Each vegetal tissue was transferred to a Petri dish containing Potato Dextrose Agar (PDA) and incubated at $28{ }^{\circ} \mathrm{C}$ for 7 days in the dark. After this period, the sample was sub-cultured several times until a pure culture was obtained, which was transferred to an inclined test tube containing PDA and maintained at $4{ }^{\circ} \mathrm{C}$.

\section{Screening and microbial identification}

On this study, 150 fungi were isolated. All the isolated fungi were allowed to grow on a liquid medium aiming at the production of lipids. The screening was divided into two parts. The first one consisted of the selection of all strains that accumulated more than 7 wt $\%$ of oil. As to the second step, fermentations at different temperatures $\left(15\right.$ and $\left.28{ }^{\circ} \mathrm{C}\right)$ were carried out with the strains from the first step, to select the strain for PUFA production. The selection of the strain in the second step was based on the amount of oil accumulated and also on the fatty acid profile.

Fermentations were carried out in Erlenmeyers containing $50 \mathrm{~mL}$ of fermentation medium at $28^{\circ} \mathrm{C}$, $120 \mathrm{rpm}$ (orbital agitation) for 7 days. The medium was constituted of $\left(\mathrm{g} \mathrm{L}^{-1}\right)$ : glucose (10.0), yeast extract (7.5), peptone (10.0), $\left(\mathrm{NH}_{4}\right)_{2} \mathrm{SO}_{4}(2.0), \mathrm{FeSO}_{4} \cdot 7 \mathrm{H}_{2} \mathrm{O}$ (1.0), $\mathrm{MnSO}_{4} \cdot \mathrm{H}_{2} \mathrm{O}(1.0)$ and $\mathrm{MgSO}_{4}(0.5)$ and the initial $\mathrm{pH}$ was adjusted to 5.8. The inoculum for fermentation was obtained by incubating the fungi on a Petri dish containing PDA for 8 days at $28^{\circ} \mathrm{C}$. Afterwards, the pure mycelia with agar was cut in three circles with diameter of $6 \mathrm{~mm}$ and transferred to the fermentation. After the fermentations, the cells 
were separated by centrifugation at $2500 \mathrm{rpm}$ for 5 minutes. The cells were washed with distilled water and further lyophilized for lipid extraction using the method suggested by Bligh and Dyer (1959).

The most promising fungus for lipid accumulation was identified by partial sequencing of nrDNA. The fungal DNA was isolated from aliquots of growth in liquid media using the ZR Fungal/Bacterial DNA Mini Prep Kit (Zymo Research). After the full extraction of the DNA, the nrDNA region (ITS1-5.8S-ITS2) for fungi was amplified with the ITS1 and ITS4 primers. The reaction for target amplification of the fragment was carried out according to Baldoni et al. (2013). Afterwards, the electrophoresis was conducted to verify the amplification in agarose gel $1.5 \%$ and buffer TBE 1X. The amplicon samples were stained with BlueGreen Loading Dye I ${ }^{\circledR}$ (LGC Biotecnologia, Cotia, Brazil) and analyzed under ultraviolet light. The PCR products were purified using the Gen Elute PCR clean-up $\mathrm{Kit}^{\circledR}$ (Sigma, Saint Louis, USA), following the instructions of the manufacturer. The sequencing of samples was carried out in the ABI PRISM 3100 Genetic Analyzer (Applied Biosystems). The sequenced fragments were analyzed using the Staden Package 2.0.0b program (Staden et al., 2003) to obtain the sequences. After this, the sequences were deposited in the GenBank and a comparative search using BLASTn was performed. For the fungi identification, all sequences were aligned in the BioEdit v7.2.5 program (Hall, 1999).

\section{Influence of the bioprocess parameters on PUFA production}

The strain with the highest lipid production selected in the previous section was used in the study sequence. In this step, glucose was replaced by sucrose as well as peptone and yeast extract by corn steep liquor (CSL). Other variables such as temperature, $\mathrm{pH}$ and agitation were also studied. A Plackett Burman design (PB12) was conceived to evaluate the influence of the process variables on the PUFA production. The ranges of variables investigated were sucrose from $60-180 \mathrm{~g}$ $\mathrm{L}^{-1}$, CSL from 5-15\%, agitation from 120-200 rpm, initial $\mathrm{pH}$ from $4-6$, and temperature from $15-25{ }^{\circ} \mathrm{C}$. The responses evaluated were biomass, lipid content, saturated fatty acids, monounsaturated fatty acids and polyunsaturated fatty acids.

The cell production for pre-inoculum was incubated on a Petri dish containing PDA for 8 days at $28^{\circ} \mathrm{C}$. Afterwards, a disc of $6 \mathrm{~mm}$ of fungal mycelium was transferred to an Erlenmeyer flask for fermentation. The fermentations were carried out on a $250 \mathrm{~mL}$ Erlenmeyer flask containing $50 \mathrm{~mL}$ of fermentation medium at $28^{\circ} \mathrm{C}$ at $120 \mathrm{rpm}$ for 7 days (Inova 44R, New Brunswick). The fermentation media was composed of sucrose and corn steep liquor compositions, according to the Plackett Burman experimental design, and a micronutrient solution constituted of ( $\mathrm{g}$ $\left.\mathrm{L}^{-1}\right)$ : $\left(\mathrm{NH}_{4}\right)_{2} \mathrm{SO}_{4}(2.0), \mathrm{FeSO}_{4} .7 \mathrm{H}_{2} \mathrm{O}(1.0), \mathrm{MnSO}_{4} \cdot \mathrm{H} 2 \mathrm{O}$ (1.0) and $\mathrm{MgSO}_{4}(0.5)$. After the fermentations, the cells were separated by centrifugation according to the previous section.

\section{Fatty acid analysis}

Lipids were extracted from the biomass according to the Bligh and Dyer method (1959). A sample of approximately $1 \mathrm{~g}$ was weighed in falcon tubes and added to $16 \mathrm{~mL}$ methanol, $8 \mathrm{~mL}$ chloroform and $6.4 \mathrm{~mL}$ distilled water and then ultra turrax homogenization was performed for $1.5 \mathrm{~min}$. The extraction occurred by stirring samples for $60 \mathrm{~min}$ at $250 \mathrm{rpm}$ in an orbital shaker. Then, $8 \mathrm{~mL}$ chloroform and $8 \mathrm{~mL}$ sodium sulfate solution $1.5 \%$ were added for phase separation and they were stirred again for $2 \mathrm{~min}$. The samples were centrifuged for $4 \mathrm{~min}$ at $3500 \mathrm{rpm}$. The organic phase containing the lipids was transferred to $10 \mathrm{~mL}$ test tubes, which were dried in vacuum at $40{ }^{\circ} \mathrm{C}$. The Hartman and Lago method (1973) was used to saponify and esterify the dried lipid extract to obtain the fatty acid methyl esters (FAME). One milliliter of methanolic potassium hydroxide $(0.4 \mathrm{M})$ solution was added to the lipid fraction and kept in a water bath at boiling temperature for $10 \mathrm{~min}$, followed by the addition of $3 \mathrm{~mL}$ of methanolic sulfuric acid (1 M) solution and subjected to the same water bath for $10 \mathrm{~min}$ again. Then, $2 \mathrm{~mL}$ of hexane were added 
and homogenized in the vortex equipment for 30 sec. Subsequently, the upper phase, containing the fatty acid methyl esters (FAME) was removed and dissolved in hexane for chromatographic analysis. The fatty acid composition was determined using a Varian 3400CX gas chromatograph (Varian, Palo Alto-CA, USA) equipped with a flame ionization detector (GCFID). $1 \mu \mathrm{L}$ of the samples was injected on the injection port in the split mode $(30: 1)$ at $250{ }^{\circ} \mathrm{C}$. The separation of FAME was carried out on a capillary column $\mathrm{SP}^{\mathrm{TM}}-2560$ (SUPELCO, Bellefonte, USA) $(100 \mathrm{~m} \times$ $0.25 \mathrm{~mm} \times 0.20 \mu \mathrm{m})$. The initial temperature of the column was set to $120^{\circ} \mathrm{C}$, which was increased up to $240{ }^{\circ} \mathrm{C}$ at a rate of $3{ }^{\circ} \mathrm{C} \mathrm{min}{ }^{-1}$ and kept at isothermal for $10 \mathrm{~min}$. The temperature of the detector was set to $250{ }^{\circ} \mathrm{C}$. FAME were identified by comparison of the retention times with those of the authentic standard FAME Mix 37 Component (Supelco, Louis-MO, USA) and quantified by area normalization.

\section{Statistical Analyses}

All statistical analyses were carried out using the Statistica ${ }^{\circledR} 7.0$ software (Statsoft Inc., Tulsa, OK, USA), considering a significance level of $90 \%$.

\section{RESULTS AND DISCUSSION}

\section{Screening and microbial identification}

Table 1 shows the lipid concentration of 150 strains of fungi isolated from the Pampa biome. Seven strains, encoded as SPII65 (11.48\%), SO71 (9.87\%), SPI42 (9.42\%), SPI11 (8.87\%), BA38 (8.21\%), SO82 (7.63\%) and SPII53 (7.25\%) accumulated more than $7 \%$ of the lipids. All strains were isolated in the Pampa biome in different regions, the strains coded as SPI11, SPII53, SPII65 and SPI42 were isolated in São Sepé-RS, that coded BA38 was isolated in Santiago-RS and those coded SO82 and SO71 were isolated in Santa MariaRS. These strains were selected for a second round of screening, where the effect of the temperature on the oil production and fatty acid profile was investigated.
Table 2 shows the lipid production, as well as the fatty acid profile obtained in the fermentations carried out at 15 and $28{ }^{\circ} \mathrm{C}$ for the seven selected strains. The lipid production ranged from 0.0 (SO71) to 6.02 wt\% (SPII65) and from 6.84 (SPII53) to $11.28 \mathrm{wt} \%$ (SPII65) at $15{ }^{\circ} \mathrm{C}$ and $28^{\circ} \mathrm{C}$, respectively. The highest lipid production was obtained with the SPII65 strain, where the amount of lipid produced at $28{ }^{\circ} \mathrm{C}$ was about $87 \%$ higher than at $15{ }^{\circ} \mathrm{C}$. The fatty acid profile was also affected by the temperature. For both evaluated temperatures, the fatty acids mostly produced by all microorganisms were palmitic $(\mathrm{C} 16: 0)$, oleic $(\mathrm{C} 18: 1 \mathrm{n}$ 9c), linoleic (C18:2n-6) and stearic acids (C18:0).

The microorganisms also produced essential fatty acids, such as linoleic (18.34-52.36\%) and $\alpha$-linolenic acids (1.06 - 7.70\%). The content of saturated fatty acids (SFA) for fermentations at $15^{\circ} \mathrm{C}$ was higher than at $28{ }^{\circ} \mathrm{C}$ (Table 2). On the other hand, the contents of MUFAs and PUFAs were higher at the temperature of $28{ }^{\circ} \mathrm{C}$. Temperature, $\mathrm{pH}$, and oxygen availability are some of the parameters that affect both growth and lipid accumulation by modifying the activity of the enzymes involved in the nutrient assimilation and lipid synthesis (Donot et al., 2014). The temperature has been reported to affect the biosynthesis of PUFAs by controlling fatty acid desaturase activities (Bellou et al., 2012; Dyal and Narine, 2005).

The production of $\alpha$-linolenic acid (C18:3n-3) was higher at $15{ }^{\circ} \mathrm{C}$ because the unsaturation of fatty acids is regulated by the temperature (Falcone et al., 2004). Silva et al. (1998) verified that low temperatures are responsible for the desaturation degree in the synthesis of C20 fatty acids by Mortierella ramanniana. The increase of the omega-3 has been explained by the role of PUFAs in increasing the membrane fluidity. At lower temperatures, more oxygen is dissolved in water and, thus, more oxygen is available for the oxygendependent desaturase enzymes (Papanikolau and Aggelis, 2011).

Analyzing the results of the lipid content and PUFA profile, the strain encoded as SPII65 showed better results at both temperatures. At $28{ }^{\circ} \mathrm{C}$, it synthesized 
Table 1. Production of lipid by fungi isolated in the Pampa biome.

\begin{tabular}{|c|c|c|c|c|c|c|c|c|c|c|c|}
\hline Code & $\begin{array}{c}\text { Lipids } \\
(\%)\end{array}$ & Code & $\begin{array}{c}\text { Lipids } \\
(\%)\end{array}$ & Code & $\begin{array}{c}\text { Lipids } \\
(\%)\end{array}$ & Code & $\begin{array}{c}\text { Lipids } \\
(\%)\end{array}$ & Code & $\begin{array}{c}\text { Lipids } \\
(\%)\end{array}$ & Code & $\begin{array}{c}\text { Lipids } \\
(\%)\end{array}$ \\
\hline SPI11 & 8.87 & SPII42 & 0.34 & BA314 & 3.33 & SO84 & 0.03 & BA21 & 4.88 & SO211 & 2.22 \\
\hline SPI43 & 3.41 & SPII13 & 0.62 & BA12 & 2.35 & SO18 & 3.32 & VP75 & 2.42 & SO75 & 0.87 \\
\hline SPII51 & 5.27 & SPII33 & 2.79 & VP86 & 2.51 & SO52 & 2.52 & VP55 & 1.30 & VP82 & 2.02 \\
\hline SPII72 & 1.61 & SPII11 & 3.30 & $\mathrm{SO} 27$ & 0.90 & SO29 & 0.33 & BA35 & 0.93 & SO12 & 1.05 \\
\hline SPII63 & 0.48 & SPII35 & 1.21 & BA53 & 4.59 & BA36 & 0.18 & SO81 & 4.88 & SO210 & 1.60 \\
\hline SPI41 & 6.32 & SPII38 & 2.11 & BA66 & 1.36 & VP47 & 0.44 & VP61 & 3.93 & SO111 & 5.53 \\
\hline SPII37 & 3.65 & SPII57 & 1.25 & BA15 & 0.35 & $\mathrm{RS} 23$ & 0.22 & SO11 & 1.61 & SO42 & 1.45 \\
\hline SPI45 & 0.85 & SPII56 & 0.07 & BA11 & 1.82 & VP77 & 1.63 & SO71 & 9.87 & SO74 & 2.22 \\
\hline SPII53 & 7.25 & SPII61 & 0.71 & BA38 & 8.21 & SO32 & 3.95 & VP85 & 2.23 & BJ & 1.35 \\
\hline SPII65 & 11.48 & SPII55 & 0.10 & OR22 & 1.68 & SO94 & 2.03 & BR31 & 1.79 & SO113 & 1.46 \\
\hline SPII54 & 5.37 & BA39 & 2.90 & BA313 & 0.99 & SO105 & 0.10 & SO210 & 1.50 & VP12 & 2.26 \\
\hline SPII64 & 5.11 & VP88 & 1.71 & BA55 & 0.69 & $\mathrm{SO} 21$ & 0.20 & BA23 & 2.32 & BA61 & 3.31 \\
\hline SPI42 & 9.42 & BA13 & 0.17 & SO13 & 1.35 & $\mathrm{RS} 27$ & 0.17 & SO104 & 1.30 & BA63 & 1.92 \\
\hline SPI14 & 3.62 & BA311 & 0.22 & SO131 & 1.99 & SO82 & 7.63 & VP61 & 2.69 & VP67 & 0.87 \\
\hline SPII36 & 3.18 & VP22 & 1.83 & BA312 & 1.72 & SO102 & 0.19 & SO41 & 3.79 & VP84 & 4.25 \\
\hline SPII43 & 5.48 & BA57 & $2 ., 35$ & BA67 & 0.43 & SO62 & 0.88 & BA31 & 0.75 & BA34 & 1.39 \\
\hline SPII23 & 3.11 & BA64 & $1 ., 81$ & SO116 & 1.00 & $\mathrm{SO} 28$ & 2.31 & VP65 & 1.04 & $\mathrm{SO} 25$ & 2.25 \\
\hline SPII62 & 1.22 & OR12 & 0.90 & BA51 & 3.95 & SO112 & 4.79 & BA58 & 0.86 & SO115 & 0.25 \\
\hline SPII32 & 0.12 & BA41 & 1.21 & VP64 & 3.40 & SO134 & 2.09 & SO91 & 1.38 & SO132 & 1.05 \\
\hline SPII22 & 2.63 & BA14 & 1.07 & SO34 & 0.27 & SO114 & 0.43 & SO122 & 1.16 & BA54 & 0.57 \\
\hline SPII36 & 0.89 & VP85 & 2.05 & SO13 & 3.93 & BA62 & 1.75 & SO74 & 1.13 & SO73 & 2.43 \\
\hline SPII14 & 5.82 & OR11 & 0.17 & OR15 & 0.02 & OR21 & 1.10 & SO72 & 0.18 & $\mathrm{RS} 21$ & 1.23 \\
\hline SPII24 & 2.07 & BA65 & 1.02 & SO31 & 0.05 & $\mathrm{SO} 72$ & 0.09 & BA52 & 0.98 & $\mathrm{RS} 24$ & 3.12 \\
\hline SPII34 & 3.06 & BA64 & 3.85 & SO54 & 2.67 & VP82 & 2.06 & SO15 & 1.34 & DF21 & 1.25 \\
\hline SPII31 & 0.62 & OR13 & 6.11 & BA37 & 2.45 & DF22 & 2.24 & DP14 & 3.33 & DP13 & 3.12 \\
\hline
\end{tabular}

$51.94 \%$ of PUFAs, with major n-6 and n-9 fatty acids produced. On the other hand, at $15{ }^{\circ} \mathrm{C}, 42.39 \%$ of PUFAs were synthesized, but with an increase of the production of n-3 fatty acids. Due to this reason, this strain was identified where the nucleotide sequences of the isolated species were compared to the NCBI database. The similarity analysis of the fragment sequences regarding the nrDNA deposited in the GenBank (KT259476) is shown in Table 3, regarding the seven fungi that presented the highest similarities with the SPII65 isolated fungi. SPII65 showed the best similarity with the Nigrospora genera. However, this result is not enough to guarantee its identification on the species level, since the region of nrDNA (ITS1-5.8S-ITS2) did not show enough interspecific nucleotidic variation to distinguish between the
Nigrospora sphaerica JQ936183 (100\% of similarity) and the Nigrospora oryzae KC954151 species (99\% of similarity). Nigrospora sp. has been isolated in the screening of fungi with potential to accumulate lipids in the study by Peng and Chen (2007); in this study, the strains were cultivated by solid-state fermentation, and $21.3 \%(\mathrm{w} / \mathrm{w})$ lipids were obtained.

\section{Influence of the process variables on PUFA accumulation}

Table 4 shows the results obtained on PB12 using the Nigrospora sp. fungus, previously selected. These data were used to determine the main effects of the variables on each response by PB12, which are shown on Figure 1 in the form of a Pareto chart. A high biomass concentration might be obtained by 


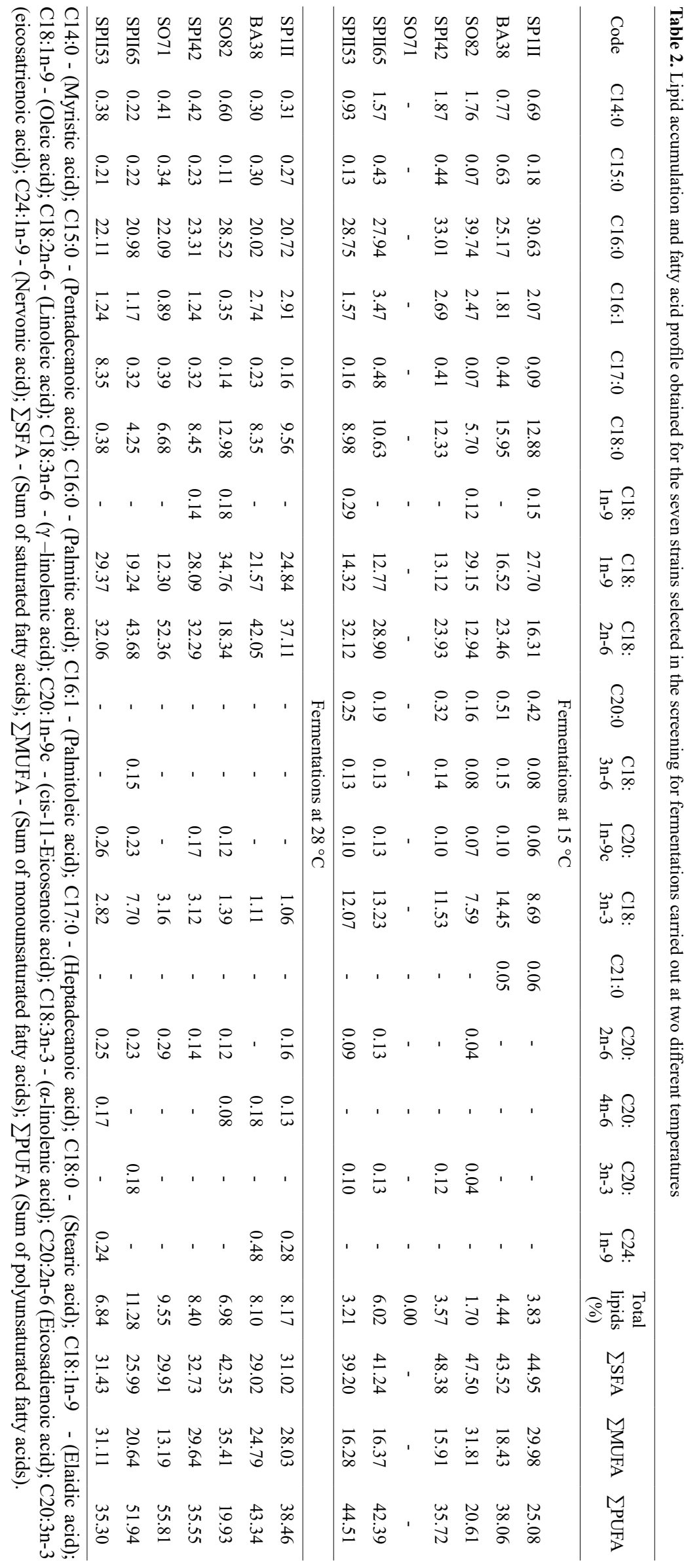


Table 3. Taxonomic identification of fungi based on the best hit and smallest genetic distance of the query sequence from the nrDNA region (ITS1-5.8S-ITS2) by similarity with the consensus fragment from isolated SPII65, using BLAST in GenBank.

\begin{tabular}{|c|c|c|c|c|}
\hline Species & Country & Access number GenBank & Similarity & Cover \\
\hline Sordariomycetes sp. & China & JX179222 & $100 \%$ & $99 \%$ \\
\hline Nigrospora sphaerica & Brazil & JQ936183 & $100 \%$ & $99 \%$ \\
\hline Nigrospora $\mathrm{sp}$. & Australia & KF227842 & $100 \%$ & $98 \%$ \\
\hline Nigrospora oryzae & Brazil & JQ936183 & $99 \%$ & $98 \%$ \\
\hline Nigrospora sphaerica & Malaysia & KM510417 & $100 \%$ & $97 \%$ \\
\hline Nigrosporasp. & China & HQ832835 & $100 \%$ & $97 \%$ \\
\hline Nigrospora sphaerica & Brazil & JQ936184 & $99 \%$ & $97 \%$ \\
\hline
\end{tabular}

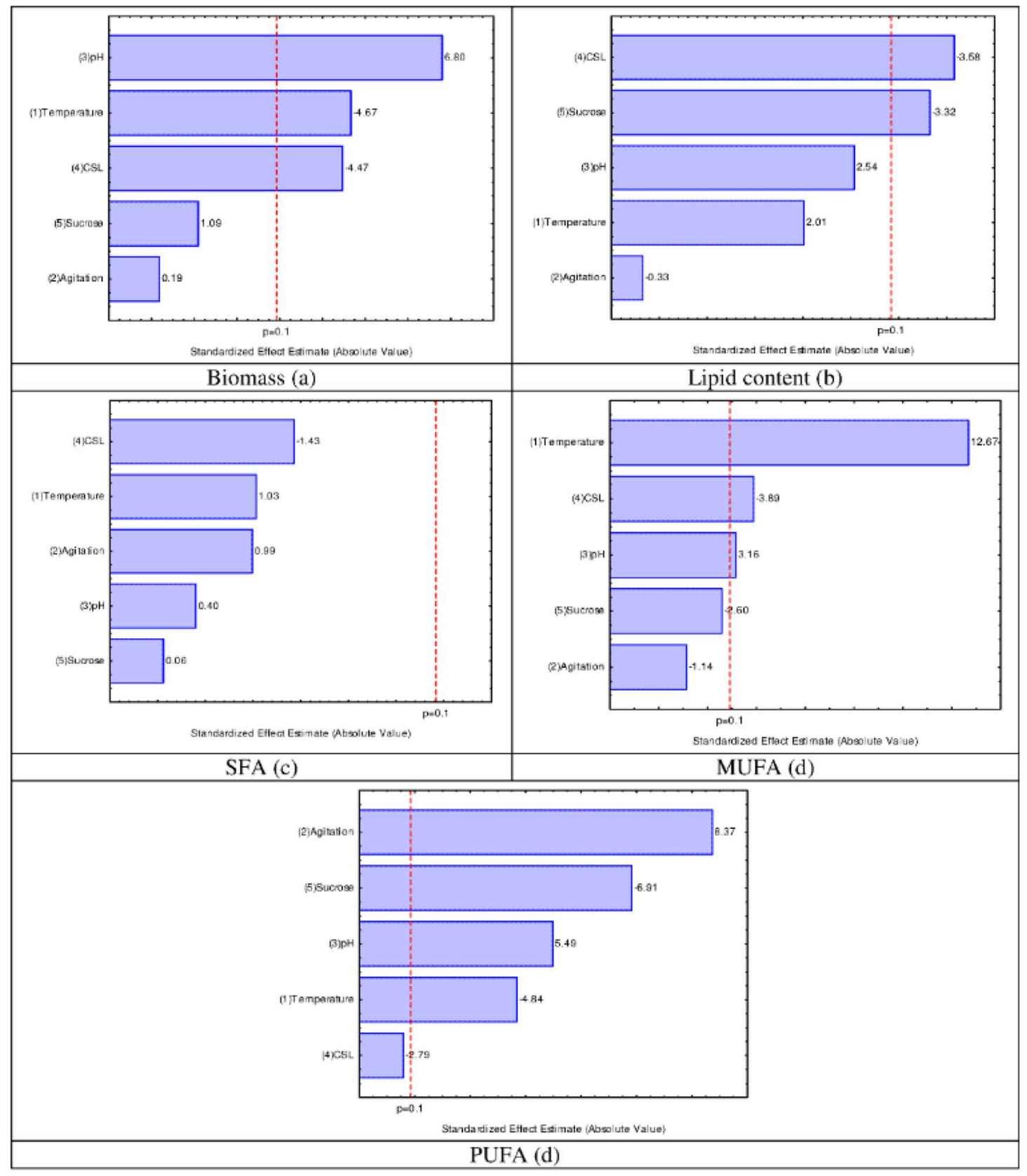

Figure 1. Pareto chart expressing the effect of process variables on biomass (a), lipid content (b), SFA (c), MUFA (d) and PUFA (d). 
Table 4. Plackett Burman experimental design, coded and real variables (in parentheses) to evaluate the biomass, lipid content and profile.

\begin{tabular}{|c|c|c|c|c|c|c|c|c|c|c|}
\hline Assay & $\begin{array}{c}\text { Temperature } \\
\left({ }^{\circ} \mathrm{C}\right)\end{array}$ & $\begin{array}{l}\text { Agitation } \\
\text { (rpm) }\end{array}$ & $\mathrm{pH}$ & $\begin{array}{c}\text { CSL }(\% ; \\
\text { v/v) }\end{array}$ & $\begin{array}{c}\text { Sucrose }(g \\
\left.\mathrm{L}^{-1}\right)\end{array}$ & $\begin{array}{c}\text { Biomass (g } \\
\left.\mathrm{L}^{-1}\right)\end{array}$ & $\begin{array}{c}\text { Lipid } \\
\text { content } \\
(\%)\end{array}$ & SFA $(\%)$ & $\begin{array}{c}\text { MUFAs } \\
(\%)\end{array}$ & $\begin{array}{c}\text { PUFAs } \\
(\%)\end{array}$ \\
\hline 1 & $1(25)$ & $-1(120)$ & $1(6)$ & $-1(5)$ & $-1(60)$ & 4.52 & 5.54 & 20.91 & 43.04 & 36.04 \\
\hline 2 & $1(25)$ & $1(200)$ & $-1(4)$ & $1(15)$ & $-1(60)$ & 2.56 & 2.45 & 25.96 & 42.68 & 31.35 \\
\hline 3 & $-1(15)$ & $1(200)$ & $1(6)$ & $-1(5)$ & $1(180)$ & 13.35 & 2.36 & 23.74 & 20.54 & 55.72 \\
\hline 4 & $1(25)$ & $-1(120)$ & $1(6)$ & $1(15)$ & $-1(60)$ & 5.42 & 2.84 & 19.08 & 41.68 & 39.22 \\
\hline 5 & $1(25)$ & $1(200)$ & $-1(4)$ & $1(15)$ & $1(180)$ & 2.64 & 2.15 & 27.70 & 28.61 & 43.40 \\
\hline 6 & $1(25)$ & $1(200)$ & $1(6)$ & $-1(5)$ & $1(180)$ & 3.90 & 3.68 & 28.26 & 43.92 & 27.82 \\
\hline 7 & $-1(15)$ & $1(200)$ & $1(6)$ & $1(15)$ & $-1(60)$ & 10.61 & 2.50 & 23.72 & 21.43 & 54.84 \\
\hline 8 & $-1(15)$ & $-1(120)$ & $1(6)$ & $1(15)$ & $1(180)$ & 7.62 & 2.38 & 32.00 & 28.32 & 39.68 \\
\hline 9 & $-1(15)$ & $-1(120)$ & $-1(4)$ & $1(15)$ & $1(180)$ & - & - & - & - & - \\
\hline 10 & $1(25)$ & $-1(120)$ & $-1(4)$ & $-1(5)$ & $1(180)$ & 9.52 & 2.04 & 32.45 & 47.96 & 19.58 \\
\hline 11 & $-1(15)$ & $1(200)$ & $-1(4)$ & $-1(5)$ & $-1(60)$ & 2.64 & 2.89 & 24.57 & 19.64 & 55.75 \\
\hline 12 & $-1(15)$ & $-1(120)$ & $-1(4)$ & $-1(5)$ & $-1(60)$ & 8.06 & 3.98 & 28.62 & 27.56 & 43.82 \\
\hline 13 & $0(20)$ & $0(160)$ & $0(5)$ & $0(10)$ & $0(120)$ & 10.19 & 3.18 & 26.92 & 36.37 & 36.72 \\
\hline 14 & $0(20)$ & $0(160)$ & $0(5)$ & $0(10)$ & $0(120)$ & 8.52 & 3.64 & 30.21 & 33.60 & 36.18 \\
\hline 15 & $0(20)$ & $0(160)$ & $0(5)$ & $0(10)$ & $0(120)$ & 9.62 & 4.48 & 38.68 & 30.44 & 31.06 \\
\hline
\end{tabular}

SFA: saturated fatty acids; MUFAs: monounsaturated fatty acids; PUFAs: polyunsaturated fatty acids; CSL: corn steep liquor.

increasing the $\mathrm{pH}$ of the medium and decreasing the temperature and CSL concentration. The reduction of the temperature and CSL concentration were shown to increase the lipid accumulation. SFA was not affected by the process variables investigated in this study. The MUFA accumulation was mainly affected by the increase of the temperature and, with minor intensity, by the decrease of the CSL concentration and the increase of the $\mathrm{pH}$. The PUFA accumulation was positively affected by increasing the agitation and decreasing the sucrose concentration and temperature.

In terms of fatty acid profile (Table 5), the main fatty acids produced among the assays were the palmitic (C16:0), oleic (C18:1), linoleic (C18:2) and stearic (C18:0) acids. Exchanging glucose (screening) by sucrose as carbon source was followed by a lipid accumulation that contained significantly higher amounts of $\alpha$-linolenic (C18:3n3), in comparison to the production levels at the highest temperature evaluated $\left(28^{\circ} \mathrm{C}\right)$. The range of fatty acids $(\mathrm{n}-6)$ produced was $30.19-43.56 \%$ and the highest productions were at lower temperatures (assay 3, 7 and 11). Chatzifragkou et al. (2010) achieved similar results with the production of palmitic (C16:0), oleic (C18:1), linoleic (C18:2), (-linolenic, palmitoleic (C16:1), and stearic (C18:0) acids in Cunninghamella echinulata and Mortierella isabellina fermentation assays.
In general, the bestresults in this step were obtained in runs 3 and 7. Under these conditions, the concentration of the biomass obtained was higher than $10 \mathrm{~g} \mathrm{~L}^{-1}$, with lipid productions of 2.36 and $2.50 \mathrm{wt} \%$ and PUFAs of 55.72 and $54.84 \%$, respectively. Additionally, in runs 3 and 7, the highest concentrations of $\alpha$-linolenic acid (C18:3n-3) were obtained (12.85 and $12.15 \%$, respectively), a fatty acid from the omega-3 family. In these runs, the ideal scenario was verified, since a high biomass concentration was obtained, producing lipids containing a high content of PUFA. This point is crucial when working with microbial lipid production, since the process productivity is strictly related to the biomass concentration and lipid content, whereas the oil quality is also related to the PUFA content.

The selected strain produced a microbial oil containing low content of omega-3 fatty acids, but present a high amount of essential fatty acids not synthesized by the human body such as linoleic acid. On the other hand, the fatty acid profile is adequate for biodiesel production. Biodiesel from microbial oil acids presents good fuel quality except for cold temperature performance due to the presense of longchain fatty acids, but this property could be improved by mixing microbial oil with oil presenting a low cold filter plugging point (Hussain et al., 2014; Ruan et al., 2012). 


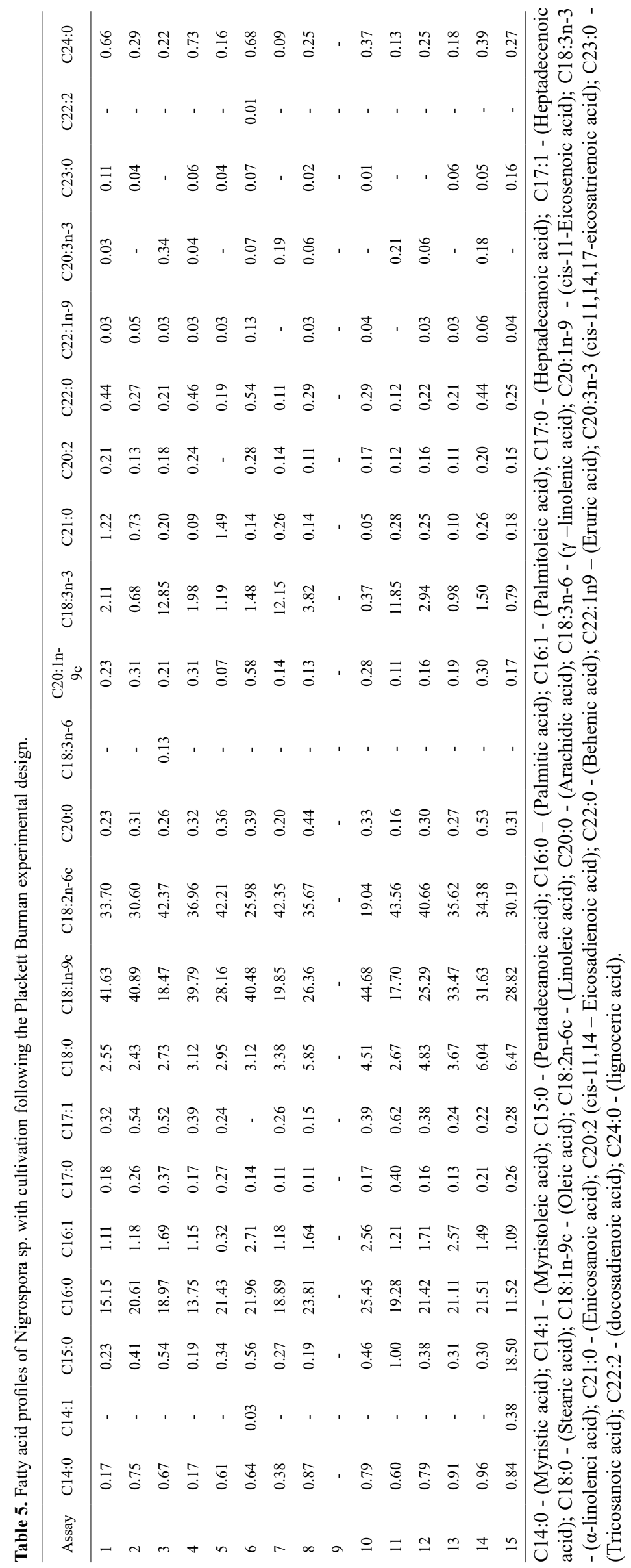




\section{CONCLUSION}

On this study, 150 fungi were isolated from the Pampa biome, targeting the production of PUFA, where the fungus encoded as SPII65 was selected as a promising strain for PUFA production. The nucleotide sequences of the SPII65 fungus were compared with the NCBI database and it was identified as belonging to the Nigrospora sp genus. The temperature showed an influence on the PUFA production, lipid accumulation and profile. The PUFA production was higher at 28 ${ }^{\circ} \mathrm{C}(51.94 \%)$ in comparison with the production at $15{ }^{\circ} \mathrm{C}$ (42.39\%). Exchanging glucose (screening) by sucrose as carbon source was followed by a lipid accumulation that contained higher amounts of $\alpha$-linolenic (C18:3n-3). The best condition for PUFA production from Nigrospora sp. was at a temperature of $15{ }^{\circ} \mathrm{C}, 200 \mathrm{~g} \mathrm{~L}^{-1}$ sucrose, initial $\mathrm{pH} 6.0,5 \mathrm{wt} \% \mathrm{CSL}$ and agitation at $180 \mathrm{rpm}$, obtaining a high biomass concentration, producing lipids that contained a high content of PUFAs.

\section{ACKNOWLEDGEMENTS}

The authors would like to thank SDECT, FAPERGS, $\mathrm{CNPq}$ and CAPES for the scholarships and financial support granted to this study.

\section{REFERENCES}

Baldoni, D. B., Coelho, G., Jacques, R. J. S., Silveira, R. M. B., Grebenc, T. and Antoniolli, Z. I., Brown rotting fungus closely related to Pseudomerulius curtisii (Boletales) recorded for the first time in South America. Mycosphere, 3, 533-541 (2013).

Béligon, V., Christophe, G., Fontanille, P. and Larroche, C., Microbial lipids as potential source to food supplements. Current Opinion Food Science, 7, 35-42 (2016).

Bellou, S., Triantaphyllidou, I. E., Aggeli, D., Elazzazy, A. M., Baeshen, M. N. and Aggelis, G., Microbial oils as food additives: recent approaches for improving microbial oil production and its polyunsaturated fatty acid content. Current Opinion Biotechology, 37, 24-35 (2016).

Bellou, S., Moustogianni, A., Makri, A. and Aggelis, G., Lipids containing polyunsaturated fatty acids synthesized by Zygomycetes grown on glycerol.
Applied Biochemical and Biotechnology, 166(1), 146-58 (2012).

Bligh, E. G. and Dyer, W. J., A rapid method of total lipid extraction and purification. Canadian Journal of Biochemistry and Physiology, 37(8), 911-917 (1959).

Chatzifragkou, A., Fakas, S., Galiotou-Panayotou, M., Komaitis, M., Aggelis, G. and Papanikolaou, S., Commercial sugars as substrates for lipid accumulation in Cunninghamella echinulata and Mortierella isabellina fungi. European Journal of Lipid Science and Technology, 112(9), 1048-1057 (2010).

Deelai, S., Suetrong, S., Damrianant, S., Unagul, P. and Sakkayawong, N., Isolation and identification of native lower fungi for polyunsaturated fatty acid (PUFA) production in Thailand, and the effect of carbon and nitrogen sources on growth and production. African Journal of Biotechnology, 14(17), 1449-1460 (2015).

Donot, F., Fontana, A., Baccou, J. C., Strub, C. and Schorr-Galindo, S., Single cell oils (SCOs) from oleaginous yeasts and moulds: Production and genetics. Biomass and Bioenergy, 68, 135-150 (2014)

Dyal, S. D. and Narine, S. S., Implications for the use of Mortierella fungi in the industrial production of essential fatty acids. Food Research International, 38, 445-467 (2005).

Falcone, D. L., Ogas, J. P. and Somerville, C. R., Regulation of membrane fatty acid composition by temperature in mutants of Arabidopsis with alterations in membrane lipid composition. BMC Plant Biology, 4, 1-17 (2004).

Hall, T. A., BioEdit: a user-friendly biological sequence alignment editor and analysis program for Windows 95/98/NT. Nucleic Acids Symposium Series, 41, 95-98 (1999).

Hartman, L. and Lago, R. C., A Rapid preparation of fatty acids methyl esters from lipids. Laboratory Practice, London, 22, 475-476 (1973).

Hussain, J., Ruan, Z., Nascimento, I. A., Liu, Y. and Liao, W., Lipid profiling and corresponding biodiesel quality of Mortierella isabellina using different drying and extraction methods. Bioresource Technology, 169, 768-772 (2014).

Lupatini, M., Jacques, R. J. S., Antoniolli, Z. I., Suleiman, A. K. A., Fulthorpe, R. R. and Roesch, L. F. W., Land-use change and soil type are drivers of fungal and archaeal communities in the 
Pampa biome. World Journal of Microbiology and Biotechnology, 29, 223-233 (2013).

Mamatha, S. S., Ravi, R. and Venkateswaran, G., Medium optimization of gamma linolenic acid production in Mucor rouxii CFR -G15 using RSM. Food and Bioprocess Technology, 1, 405 - 409 (2008).

Papanikolau, S. and Aggelis, G., Lipids of oleaginous yeasts. Part I: Biochemistry of single cell oil production. European Journal of Lipid Science and Technology, 113(8), 1031-1051 (2011).

Peng, X. W. and Chen, H.Z., Microbial oil accumulation and cellulase secretion of the endophytic fungi from oleaginous plants. Annals of Microbiology, 57, 239-242 (2007).

Pote, S. and Bhadekar, R., Statistical approach for production of PUFA from Kocuria sp. BRI 35 isolated from marine water sample. BioMed Research International 14:1-9 (2014).

Pylro, V. S., Roesch, L. F., Ortega, J. M., doAmaral, A. M., Tótola, M. R., Hirsch, P. R., Rosado, A. S., Góes-Neto, A., Silva, A. L., Rosa, C. A., Morais, D. K., Andreote, F. D., Duarte, G. F., Melo, I. S., Seldin, L., Lambais, M. R., Hungria, M., Peixoto, R. S., Kruger, R. H., Tsai, S. M. and Azevedo, V., Brazilian Microbiome Project: Revealing the
Unexplored Microbial Diversity-Challenges and Prospects. Microbial Ecology, 67, 237-241 (2014).

Ratledge, C. and Wynn, J., The biochemistry and molecular biology of lipid accumulation in oleaginous microorganisms. Advances in Applied Microbiology, 51, 1-51 (2002).

Ruan, Z., Zanotti, M., Wang, X., Ducey, C. and Liu, Y., Evaluation of lipid accumulation from lignocellulosic sugars by Mortierella isabellina for biodiesel production. Bioresource Technology, 110, 198-205 (2012).

Staden, R., Judje, D. P. and Bonfield, J. K., Managing sequencing projects in the GAP4 environment. In: Krawetz, S. A., Womble, D. D. Introduction to Bioinformatics. A Theoretical and practical approach. Human Press Inc, Totawa (2003).

Sette, L. D., Pagnocca, F. C. and Rodrigues, A., Microbial culture collections as pillars for promoting fungal diversity, conservation and exploitation. Fungal Genetics and Biology, 60, 2-8 (2013).

Silva, M., Manfio, G. P. and Canhos, V. P., Characterization of selected strains of mucorales using fatty acid profiles. Revista Microbiologia 29, 276-281 (1998). 
